\title{
HIGHLY PURIFIED WOOD FIBERS AS PAPER-MAKING MATERIAL
}

\author{
By Royal H. Rasch, ${ }^{1}$ Merle B. Shaw, and George W. Bicking
}

\section{ABSTRACT}

A semicommercial scale study has been made at the National Bureau of Standards of the manufacture of bond types of papers from commercial highly purified wood fibers for uses requiring permanency. As a part of the investigation, the experimental papers produced were tested for strength, chemical purity, and aging properties. The strength tests included bursting, tensile, and tearing strength and folding endurance. The chemical-purity tests included alpha cellulose content, copper number, acidity, and quantitative tests for the sizing materials present. The accelerated aging test used consisted of heating the papers in air to a temperature of $100^{\circ} \mathrm{C}$. for 72 hours, and then measuring the extent of change in the various strength and chemical properties.

By studying the effects of variations in beating conditions on the properties of finished papers a method of beating well adapted for this kind of fiber was evolved. The papers had excellent strength properties, exceeding, in the case of the bond papers, the strength requirements of the highest-grade bond papers purchased by the Government Printing Office (U. S. A.) and, in the case of the currency-type papers, the strength requirements for United States currency. The experimental papers possessed also other characteristics desirable in these types of papers.

Some of the possible factors influencing the aging properties which arise in the process of converting pulp into paper were studied, including effects of beating; alum (acidity), rosin, and starch used in beater sizing; and glue, starch, alum, and formaldehyde used for surface sizing. The amount of beating required to produce the desired characteristics in the papers had no apparent effect upon the chemical properties of the fibers or upon their stability. A definite relation between the acidity of the rosin-sized papers and their stability was noted. A marked lowering in stability was caused by the use of excessive amounts of alum. By careful control of the acidity of the stock in the beater-i. e., amount of alum added to the beater-it was possible to prepare well-sized papers of very high stability. Other factors being alike, papers with the lowest rosin content had the best resistance to accelerated aging. In general the addition of starch in the beater caused an increase in the strength of the paper and had no deleterious effect upon the stability of the finished paper. The effects produced were practically the same for the two kinds of starch products used, one prepared by a process of acid hydrolysis and the other by a process of oxidation.

Unsized and rosin-sized papers were surface sized with glue and starch solutions. In general the bursting strength, tensile breaking strength, and elongation increased on surface sizing and the tearing strength decreased proportionally with the amount of size taken up by the basic paper. No such relation appeared to hold in the case of the folding endurance, which increased on surface sizing about 10 per cent on the average. In the case of the currency type papers, which had exceptionally high folding endurances before sizing, a slight decrease in folding endurance on surface sizing with glue was noted. For the specific samples of glue and starch used in this work, little difference in the final results obtained with them was noted. In general the stability of the papers toward accelerated aging was improved by surface sizing. This protective effect was somewhat more pronounced in the case of glue sizing than in the case of starch sizing. When alum was used in moderate amounts as a preservative for the glue or starch in the surface-sizing baths, it caused no deleterious effect on the paper as far as could be determined by the tests applied. 


\section{CONTENTS}

I. Introduction

1. Previous study of highly purified wood fibers

2. Purpose and plan of investigation

II. Paper-making equipment_...

III. Paper-making processes.

1. Beating and paper-making operation

2. Beater sizing

(a) Rosin

(b) Starch........ 768

3. Surface sizing

(a) Glue

(b) Starch...... 768

IV. Test methods

1. Methods of the Technical Association of the Pulp and Paper Industry -

2. Chemical testing methods

(a) Titratable acidity

(b) $\mathrm{pH}$ of paper extracts

(c) Alpha cellulose content and copper number.....

3. Accelerated aging test. .

V. Tests on paper-making fiber used

VI. Manufacturing details and test data for papers

1. Unsized papers

(a) Hand sheets

(1) Effect of beating on development of

(2) Effect of beating on the alpha cellulose content and copper number.........

(b) Machine-made papers

2. Beater-sized papers

(a) Rosin-sized

(b) Starch-sized

3. Surface-sized papers

(a) Bond type

(1) Basic papers for surface sizing

(2) Surface-sizing baths.....

(b) Currency type.

\section{INTRODUCTION}

\section{PREVIOUS STUDY OF HIGHLY PURIFIED WOOD FIBERS}

In 1928 the National Bureau of Standards began a program of research on the study of highly purified wood fibers for the purpose of determining their value as a raw material for the manufacture of high-grade papers. These are wood fibers which have been refined to a high state of cellulosic purity as measured by such tests as copper number and alpha cellulose content. The first part of this investigation, which has already been published, ${ }^{2}$ dealt with a comparative study of high purified wood fibers and papers prepared from them, and other types of paper-making fibers and papers, mostly commercial. The results of this work indicated that wood fibers can be obtained with sufficient strength and purity for conversion into the higher grades of writing papers where durability and longevity are essential requirements.

I R. H. Rasch, A Study of Purified Wood Fibers as a Paper-Making Material, B. S. Jour. Research, vol. 3 (RP 107), pp. 469-506, September, 1929. 


\section{PURPOSE AND PLAN OF INVESTIGATION}

The conclusions drawn in the publication referred to were necessarily somewhat limited, because of the fact that complete information was not available as to the history of the various papers and papermaking raw materials tested. In the ordinary course of commercial production it is difficult to obtain important data on the many variables in manufacture which may influence markedly the permanence of paper and its ability to withstand continual handling. Therefore it was considered desirable to supplement the tests of commercial papers with similar tests of papers made in the bureau paper mill under carefully controlled conditions, where complete data on the various steps in the manufacturing processes could be obtained. The plan of investigation adopted includes unit studies of all the important types of commercial chemical wood fibers and rag fibers commonly used in the manufacture of record papers by means of their conversion into papers under semicommercial mill conditions, and subsequent thorough testing of these papers. It was realized that some incidental study of the important variables involved, such as beating and sizing operations, and, in the case of rag half-stock preparation, cooking and bleaching, would be necessary in order to gain the information required to develop the optimum qualities in papers prepared from each of the fibrous raw materials under consideration.

Knowing the exact details of manufacture and the test results obtained on papers manufactured under those conditions, it was expected that definite information could be obtained on the various fibers with respect to (1) the highest quality of paper possible to make from each of them under favorable conditions, (2) how to obtain this quality, and (3) the manner and the extent to which the quality of the paper is affected by the raw materials and by the variations commonly encountered in processing them.

This paper deals with such study of a grade of commercial highly purified wood fibers prepared particularly for use in such papers as bonds and ledgers. Richter has recently reported on the results of a similar investigation of the durability of purified wood fibers. ${ }^{3}$ Similar tests of other types of fibers are in progress.

\section{PAPER-MAKING EQUIPMENT}

The bureau paper mill contains complete equipment for the manufacture of practically all types of paper under conditions which simulate those of industrial mills. Complete descriptions as well as photographs of this equipment may be found in previous bureau publications. ${ }^{4}$

\section{PAPER-IIAING PROCESSES}

\section{BEATING AND PAPER-MACHINE OPERATION}

Details of the beating and paper-machine operations as carried out in the bureau paper mill are thoroughly described in previous publications. ${ }^{5}$

${ }^{3}$ Durability of Purified Wood Fibers, Jour. Ind. Eng. Chem., 23, No. 4, pp. 371-380, April, 1931.

- M. B. Shaw and G. W. Bicking, Caroá Fiber as a Paper-Making Material, B. S. Tech. Paper No. 340; also $M$. B. Shaw, Equipment and Research Work of the Bureau of Standards Papar Mill, Paper Trade Jour., vol. 89, No. 19, pp. 60-63, Nov. 7, 1929.

J. B. Shaw and G. W. Bicking, Research on the Production of Currency Paper in the Bureau of Standards Experimental Paper Mill, B. S. Tech. Paper No. 329, and Further Exparimental Production of Currency Papar in the Bureau of Standards Paper Mill. B. S. Jour. Research, vol. 3 (RP 121), pp. 899-926, December, 1929. 


\section{BEA'TER SIZING}

(a) ROSIN

Rosin is the material most widely used for sizing the fibers in the beater to impart water resistance to paper. The size is made by digesting rosin with soda ash $\left(\mathrm{Na}_{2} \mathrm{CO}_{3}\right)$ or caustic soda $(\mathrm{NaOH})$ to form the sodium salt, a solution of which is added to the stock in the beater. Rosin is precipitated onto the fibers by subsequent addition of paper-maker's alum, aluminum sulphate, $\mathrm{Al}_{2}\left(\mathrm{SO}_{4}\right)_{3} .18 \mathrm{H}_{2} \mathrm{O}$. The rosin size used in the present work contained about 33 per cent free rosin, held emulsified in the solution of sodium resinate.

\section{(b) STARCH}

When starch is used in the beater it is practically always used in conjunction with rosin size, as it does not itself impart water-resistant properties to paper. Two general types of commercial beater starch were used in this work; one said to be prepared by a process of acid hydrolysis, the other by an oxidation process.

In preparing the starch paste and in adding it to the beater the aim was to approximate the current commercial practice as far as possible. In making the paste, 1 part of starch (air-dry) was allowed to soak for about one-half hour in about 5 parts of cold water, after which time the mixture was brought up to a temperature between $140^{\circ}$ and $160^{\circ} \mathrm{F}$. It was kept at this temperature until the starch had swelled to the proper extent, and then was cooled. When used together with rosin size, the starch paste was added to the beater one hour after the latter and one hour before the addition of alum.

\section{SURFACE SIZING}

Most high-grade bond and ledger papers are surface coated with a film of glue or starch to improve the writing quality, resistance to wear, and various other properties.

\section{(a) GLUE}

The glue sizing bath consisted of a 4 per cent solution of a highgrade hide glue. In order to observe the effect of alum on the properties of the papers, sizing treatments were made with and without the presence of alum. In one experiment the use of formaldehyde as a preservative was tried. The sizing baths were maintained at approximately $130^{\circ} \mathrm{F}$. The paper to be sized was passed through the heated solution, then between a pair of squeeze rolls to remove excess size, and finally dried in a festoon drier at a temperature of $110^{\circ}$ to $120^{\circ} \mathrm{F}$. The desired finish was imparted to the paper by supercalendering.

\section{(b) STARCH}

The procedure for surface sizing with starch was essentially the same as that for sizing with glue. As in the case of beater sizing, two types of commercial starch were used, one prepared by a process of acid hydrolysis, the other by an oxidation process. In preparing the solution for sizing, 1 part of starch was allowed to soak for one-half hour in 4 parts of cold water, and then the mixture was heated to a temperature of $165^{\circ} \mathrm{F}$. When the proper swelling had taken place, sufficient water was added to make a 4 per cent solution. 


\section{TEST METHODS}

\section{METHODS OF THE TECHINAL ASSOCIATION OF THE PULP AND} PAPER INDUSTRY ${ }^{6}$

The official T. A. P. P. I. methods for determining weight, bursting strength, thickness, folding endurance, tensile breaking strength, tearing strength, opacity, ash, resin, starch, and glue were used. The methods for sizing quality ${ }^{7}$ and wet rub $^{8}$ were those developed at the bureau.

\section{CHEMICAL TESTING METHODS}

\section{(a) TITRATABLE ACIDITY}

Determinations of the titratable acidity were made on extracts of ground paper (Kohler-Hall method) ${ }^{9}$ and directly on suspensions of the ground paper. Both procedures were outlined in a previous publication. ${ }^{10}$

\section{(b) PH OF PAPER EXTRACT}

The $\mathrm{pH}$ of the papers was determined colorimetrically on extracts of the ground samples with the Acree-Fawcett isohydric indicators. ${ }^{11}$ It has been found that many of the extracts of paper are so weakly buffered or so dilute that their $\mathrm{pH}$ value is noticeably altered by the addition of the overneutralized commercial indicator solutions. In order to avoid this source of error, the isohydric indicator method was employed. These indicators are adjusted at intervals of 0.2 $\mathrm{pH}$ throughout their effective range. By preliminary trials the approximate $\mathrm{pH}$ of the unknown is located; then the final determination is made with an indicator of that $\mathrm{pH}$.

The procedure used for preparing extracts of the paper for $\mathrm{pH}$ measurement was as follows: Into a suitable Pyrex flask containing $2.5 \mathrm{~g}$ of the air-dry ground paper sample was added $125 \mathrm{ml}$ of boiling distilled water. The flask was fitted with an air condenser and placed in a steam bath. During the period of digestion the flask was shaken occasionally to keep the fibers distributed. At the end of one hour the suspension was poured onto a Büchner funnel. The filtrate was returned through the fiber pad formed on the funnel in order to remove any fibers. This clear filtrate was poured immediately into a $125 \mathrm{ml}$ Erlenmeyer flask which was tightly stoppered. The test for $\mathrm{pH}$ was made as soon as the extract attained room temperature.

\section{(c) ALPHA CELLULOSE CONTENT AND COPPER NUMBER}

The alpha cellulose content and copper number procedures used were described in detail in a recent publication, which reports the results of a study made to develop improved procedures. ${ }^{12}$

- Copies of the paper-testing methods of the Technical Association of the Pulp and Paper Industry may te obtained from the secretary, at 370 Lexington Avenue, New York, N. Y.

7 F. T. Carson, Measurement of the Degree of Sizing of Paper, B. S. Tech. Paper No. 326.

- F. T. Carson and F. V. Worthington, A Wet Rub Tester for Paper, Paper Trade Jour., vol. 84, No. 2, pp. 45-46, Jan. 13, 1927.

Kohler-Hall, Acidity in Paper, Paper Industry, vol. 7, No. 7, pp. 1-5, October, 1925.

$11 \mathrm{R}$. H. Rasch, Accelerated Aging Test for Paper, B.'S. Jour. Research, vol. 7 (RP 352), pp. 465-475, September, 1931.

1I S. F. Acree and Edna H. Fawcett, The Problem of Dilution in Colorimetric H-Ion Measurements-I. Isohydric Indicator Methods for Accurate Determination of $\mathrm{pH}$ in Very Dilute Solutions, and II. Use of Isohydric Indicators and Superpure Water for Accurate Measurement of Hydrogen-Ion Concentrations and Salt Errors. Parts I and II published, respectively, in Jour. Bacteriology, 17, No. 3, pp. 163-204; March, 1320, and Jour. Ind. Eng. Chem. (analytical edition), vol. 2, No. 1, pp, 78-85, Jan. 15 , 1930.

11 J. O. Burton and R. H. Rasch, The Determination of the Alpia Cellulose Content and Copper Number of Paper, B. S. Jour. Research, vol. 6 (RP 295), pp. 603-619, A pril, 1931. 


\section{ACCELERATED AGING TEST}

The accelerated aging test or stability test employed in the present study consists of exposing the paper specimen under examination to a current of air at $100^{\circ} \mathrm{C}$. for 72 hours and then observing to what extent the paper is altered in its several properties. The assumption made is that the changes produced in the paper parallel those produced under more normal conditions sufficiently to permit estimates of the probable relative longevity of papers. In a recent publication it was shown that this test arranged a series of Government writing papers of various grades in the expected order of permanence. ${ }^{13}$

In the present study physical and chemical tests previously outlined and described were made on the original papers. For the purpose of studying the aging qualities of the various papers the bursting strength, tensile breaking strength, per cent elongation at rupture, folding endurance, tearing strength, alpha cellulose content, and copper number were determined on the papers both before and after they had been subjected to the heat treatment. It is well known that paper may vary considerably in strength at different areas; therefore care was taken that the sample used for the heat test should be as nearly representative of the control sample as possible. In this work 10 sheets (101/2 by 16 inches), so selected as to be representative of the whole machine run or tub sizing run, as the case happened to be, were divided into two sets, $10 \frac{1}{2}$ by 8 inches. One half was used for the control tests, the other half was subjected to heat treatment and subsequent testing. The portions of paper left over from the strength tests were ground for the chemical tests. This method of sampling seemed to be adequate for all the strength tests with the exception of the folding endurance. In the latter case further precautions were taken designed to minimize the possibility of large errors. The details of this procedure will be the subject of a subsequent report. Duplicate aging tests of 13 different papers using this procedure showed that the maximum variation of the retention value (ratio of folding endurance of heated paper to folding endurance of original paper) from the average was 10 per cent, and that the average variation for all papers was 4 per cent.

\section{TESTS OF PAPER-MAKING FIBER USED}

All the experimental papers prepared in the bureau paper mill for this work were made from the same lot of highly purified wood fibers representative of a commercial product. A representative sample of this pulp was tested, with results as given in Table 1.

TABLI 1. - Tests of paper-making fiber used

\begin{tabular}{|c|c|c|}
\hline & $\begin{array}{l}\text { Original } \\
\text { sample }\end{array}$ & $\begin{array}{c}\text { Sample } \\
\text { heated at } \\
100^{\circ} \mathrm{C} \text {. for } \\
72 \text { hours }\end{array}$ \\
\hline $\begin{array}{l}\text { Alpha cellulose content } \\
\text { Beta cellulose content }\end{array}$ & $\begin{array}{c}\text { Per cent } \\
091.9 \\
2.9\end{array}$ & $\begin{array}{c}\text { Per cent } \\
\quad 91.6\end{array}$ \\
\hline Gamma cellulose content.... & 5.2 & 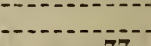 \\
\hline $\begin{array}{l}\text { Copper number } \\
\text { Pentosans }\end{array}$ & $\begin{array}{l}.64 \\
3.50\end{array}$ & .77 \\
\hline Resin & .27 & - \\
\hline & & \\
\hline
\end{tabular}

a The sarne determination made on 1/4-inch square of the pulp sheet gave a result of 93.7 per cent. Many methods for the determination of alpha cellulose content, including the tentative standard method of the American Chemical Society, specify that the sample shall be in the form of squares.

12. See footnote 10, p. 769. 


\section{MANUFACTURING DETAILS AND TEST DATA FOR PAPERS}

\section{UNSIZED PAPERS}

(a) HAND SHEETS

(1) Effect of Beating on Development of Strength ProPERTIES.-The character and many properties of paper, particularly : trength, are determined in large part by the beating technic employed. The duration of beating and the manner of lowering the beater roll are both factors of importance in producing the desired strength characteristics in the paper. The treatment given the fibers in the beater differs considerably for different fiber materials and according to the type of paper being made. Some fibers "hydrate" very rapidly

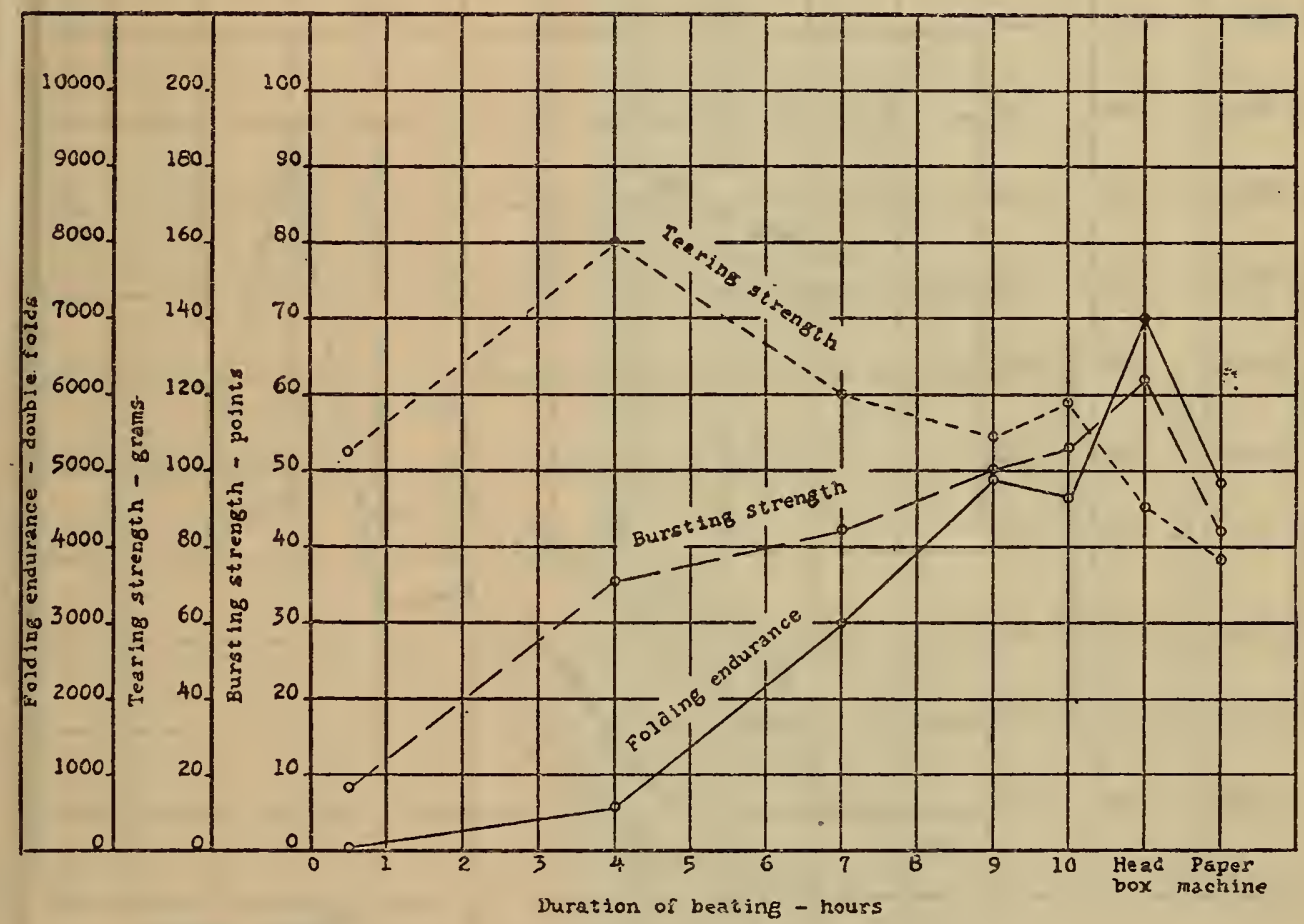

FIGURE 1.-Strength properties of hand sheets

Head box-Jordan and screened stock. Paper machine-test results on paper-machine products.

others exceedingly slowly. This study was confined to the development of types of high-grade writing papers, and therefore it was necessary to determine the beating procedure best designed to impart the high strength and other desirable characteristics important to this kind of paper.

The progressive development of strength with beating may frequently be satisfactorily and more conveniently studied by converting the fibers into hand test sheets, instead of by the slower and more expensive process of converting them into paper on a paper machine. In the present study hand sheets of stock taken at different intervals throughout the course of a beating were made. The strength values obtained on two runs are presented in Figures 1 and 2, which are typical of those obtained on several such runs. Standardized equipment and procedures have been developed at the bureau for the preparation of fiber hand sheets. For a detailed description of the pro- 
cedure the reader is referred to an earlier publication containing that information. ${ }^{14}$

Figure 1 shows the maximum folding endurance was reached in approximately 9 to 10 hours of beating. The development of bursting strength followed along roughly with that of folding endurance. The tearing strength, however, reached its maximum in 3 to 4 hours and then decreased with further beating. While the folding endurance is considered the best indication of a paper's resistance to wear, it is essential that this factor be not developed to the disadvantage of the other desirable properties. In this case it was decided that a better balance between the folding endurance and the tearing strength would be had if the duration of beating were somewhat short of that

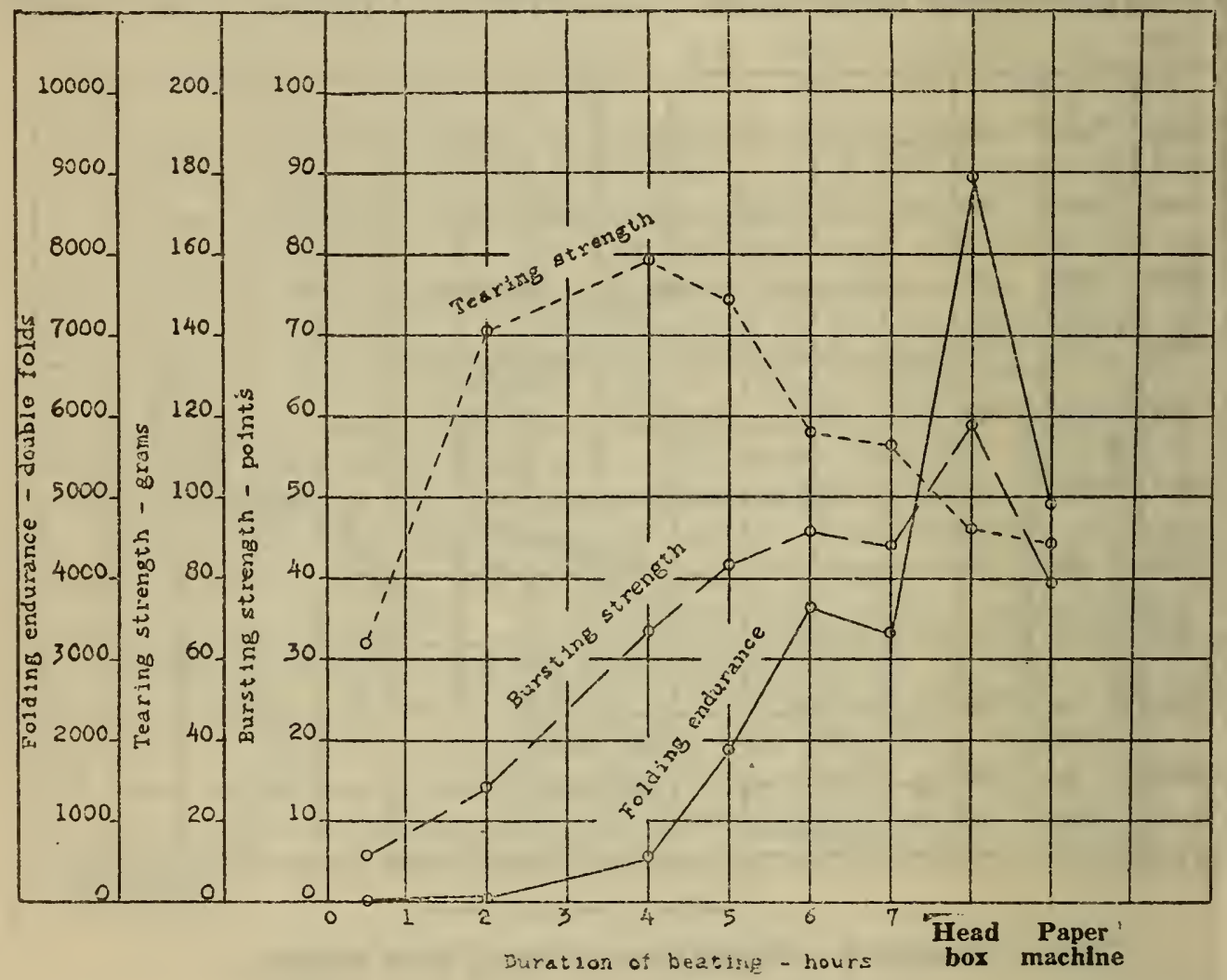

FIGURE 2.-Strength properties of hand sheets

Head box-Jordaned and screened stock. Paper machine-test results on paper-machine products.

required to give the maximum folding endurance and bursting strength. With excessive beating it would seem that an increased formation of cellulose gel takes place. While this material, by virtue of its cementing properties, increases the folding endurance and bursting strength, it decreases the tearing strength and the opacity, and, further, may have an undesirable hardening effect upon the paper. The most desirable kind of beating for bond papers is probably one which is sufficiently prolonged to develop the maximum felting properties, through brushing out and fraying of the fibers, but not so prolonged or drastic as to result in much cutting of the fibers or in the development of excessive amounts of cellulose gel.

11 M. B. Shaw, G. W. Bicking, and L. W. Snyder, The Preparation of Fiber Test Sheets, B. S. Jour. Research, vol. 5 (RP190), pp. 105-114, July. 1930. 
(2) Effrect of Beating on the Alpha Cellulose Content and Copper NuMBer.-A 2 per cent suspension of fibers was beaten in a small beater. Portions of the stock were taken out at the following intervals: (1) After a few minutes of beating, (2) after $2 \frac{1}{2}$ hours of beating, (3) after 5 hours of beating, and (4) after $7 \frac{1}{2}$ hours of beating. Hand sheets were made from each of these portions. The alpha cellulose content and copper number were determined on squares of the sheets and also on the ground material. The data obtained, which are presented in Table 2 , indicate that the beating caused practically no change in the chemical properties of the fibers measured by these tests.

TABLE 2.-Effect of beating on the alpha cellulose content and copper number. ${ }^{1}$

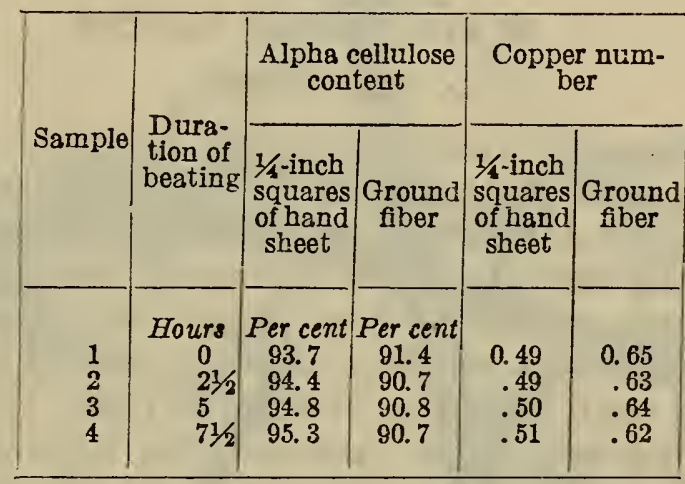

1 The beating was done in a laboratory beater.

(b) MACHINE-MADE PAPER

Table 3 gives data relative to the operation of the beater and the test results of the machine-made papers.

The results indicated that a 7-hour beating, with the method of roll manipulation found most suitable, would give a satisfactory balance of the various desired properties in the paper. A light jordanning of the beaten stock appeared to be of advantage. This interval of beating offers a sufficient time for the gradual and proper brushing out of the fibers to be accomplished before excessive "hydration" has taken place. In Figure 3 a photomicrograph is shown of fibers beaten seven hours. The jordanned stock is shown in Figure 4. These photomicrographs show this fiber may be satisfactorily fibrillated and frayed if properly beaten. An outline of the beating procedure selected as suitable for this type of fiber is given in Table 4. This procedure was used for all subsequent runs.

In regard to the stability of the unsized paper, it appears that these papers are almost entirely resistant to treatment at $100^{\circ} \mathrm{C}$. for 72 hours. Under these conditions there is a very slight decrease in the alpha cellulose content, a correspondingly slight increase in the copper number, and practically no change in the strength properties. No appreciable yellowing of the paper occurs. These are considered favorable indications of permanence. Tests of commercial papers made from less pure fibers show that they may lose practically all their initial folding endurance and decrease as much as 8 per cent in alpha cellulose content on heat treatment. 
TABLE 4.-Schedule of roll settings for beating

\begin{tabular}{|c|c|c||c|c|c|}
\hline Beating interval & $\begin{array}{c}\text { Posi- } \\
\text { tion of } \\
\text { roll i }\end{array}$ & Beating interval & $\begin{array}{c}\text { Posi- } \\
\text { tion of } \\
\text { roll 1 }\end{array}$ \\
\cline { 1 - 3 } Hours & Minutes & & Hours & Minutes & \\
0 & 0 & 10 & 2 & 30 & $1 / 2$ \\
0 & 15 & 10 & 3 & 0 & 0 \\
0 & 30 & 4 & 4 & 0 & 0 \\
1 & 0 & 2 & 5 & 0 & 0 \\
1 & 30 & $11 / 2$ & 6 & 0 & $-1 / 2$ \\
2 & 0 & 1 & 7 & 0 & $-1 / 2$ \\
\hline
\end{tabular}

${ }^{1}$ Indicated as turns of the hand wheel with which the position of the roll relative to the bed plate is changed. At the $-1 / 2$ setting the roll impinges on the bedplate, and at the zero setting the bedplate is just barely cleared. One turn of the hand wheel raises or lowers the roll 0.008 inch.

\section{BEATER SIZED PAPERS}

(a) ROSIN-SIZED

'The necessity for employing minimum amounts of rosin and alum in the sizing of papers intended for permanent use is now generally recognized. The machine runs described below were made for the purpose of studying the effect of rosin sizing, particularly the acidity of rosin-sized papers. Each of four papers was sized with 2 per cent rosin, while the amounts of alum used to precipitate the size were varied from 1 per cent, based on weight of fiber, to 4 per cent. The duration of beating and other factors were kept constant as far as possible. Two control runs were made in which the amounts of alum added to the stock were varied, but in which no rosin was employed. Table 3 contains the data relative to the beating interval, sizing of the stock, and tests of the machine-made papers.

In run No. 783 a large excess of alum over that required for adequate sizing was purposely added. The finished paper, which had a $\mathrm{pH}$ of 3.7, discolored appreciably and underwent marked changes in strength and chemical properties when subjected to the accelerated aging test. The unsized paper of run No. 781, which corresponded to run No. 783 in all respects except that no rosin size was present, was on the whole much more stable and discolored but slightly on heating, indicating that rosin sizing may contribute a deteriorative. effect in addition to that of the acid.

In run No. 766, only one-half the amount of alum used in the previous run was employed, with a resulting improvement in stability. The $\mathrm{pH}$ of this paper was 4.2. The amount of alum used was still further reduced in runs Nos. 771 and 772 . These papers had $\mathrm{pH}$ values of 5.2 and 5.4, respectively, and were found to be very stable toward accelerated aging. While the former was satisfactorily sized, the latter was somewhat deficient in this respect. Therefore, under the existing conditions, the optimum $\mathrm{pH}$ value combining high stability with adequate sizing appears to be approximately 5.0 .

In general the agieement between the pH values of stock at the head box and extracts of the finished paper was fairly good. The widest discrepancies occurred in the case of the more nearly neutral papers. In the case of run No. 772 the $\mathrm{pH}$ of the stock at the head box was 6.5, while that of the extract of finished paper was 5.4. This wide difference is probably due to the fact that in the measurement of the $\mathrm{pH}$ of the head-box stock the unadjusted rather than the isohydric type of indicators was used. 


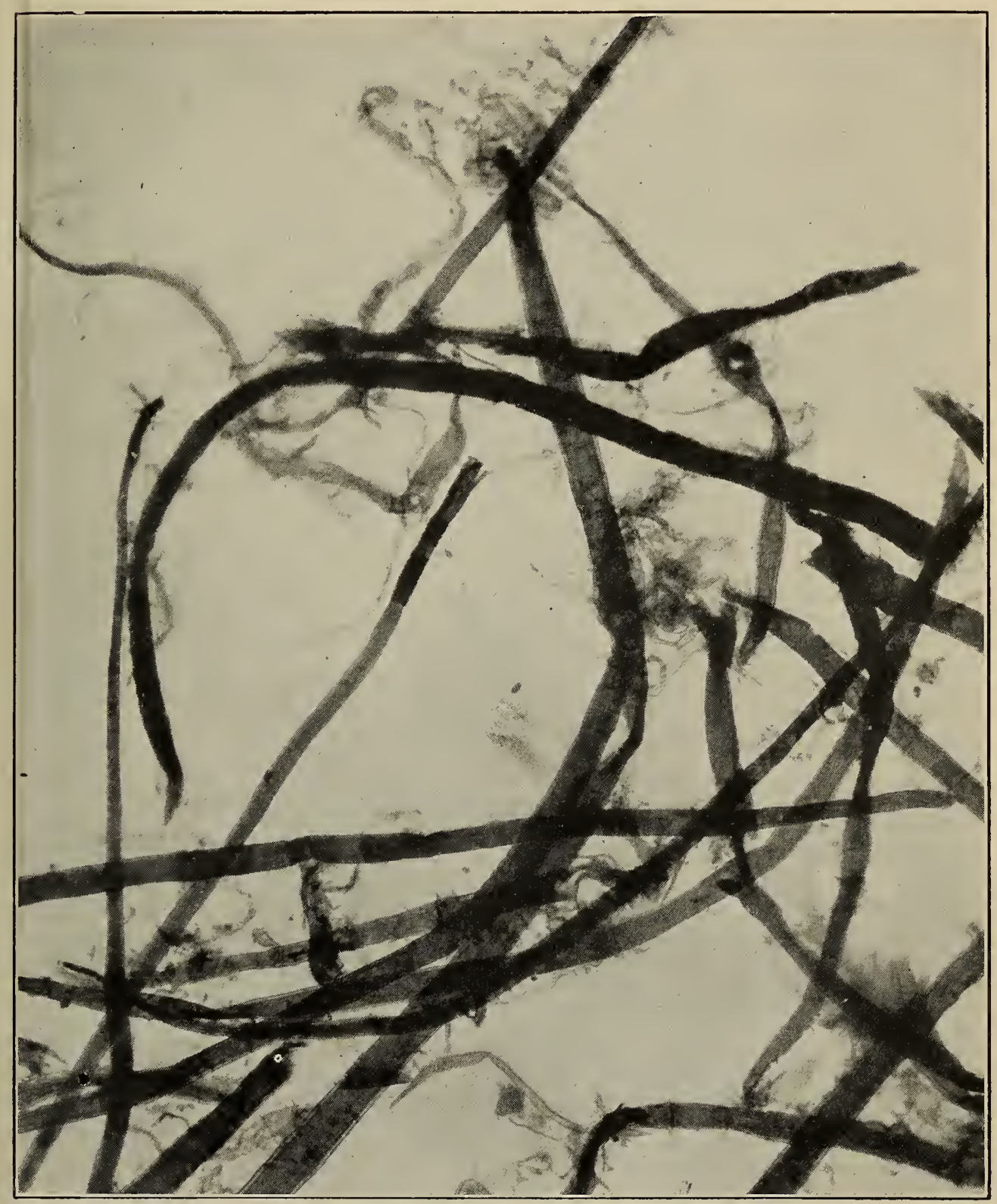

FiguRe 3.-Highly purified wood fiber, $\times 100$

After completion of beating ( 7 hours). Before jordanning. 
B. S. Journal of Research, RP372

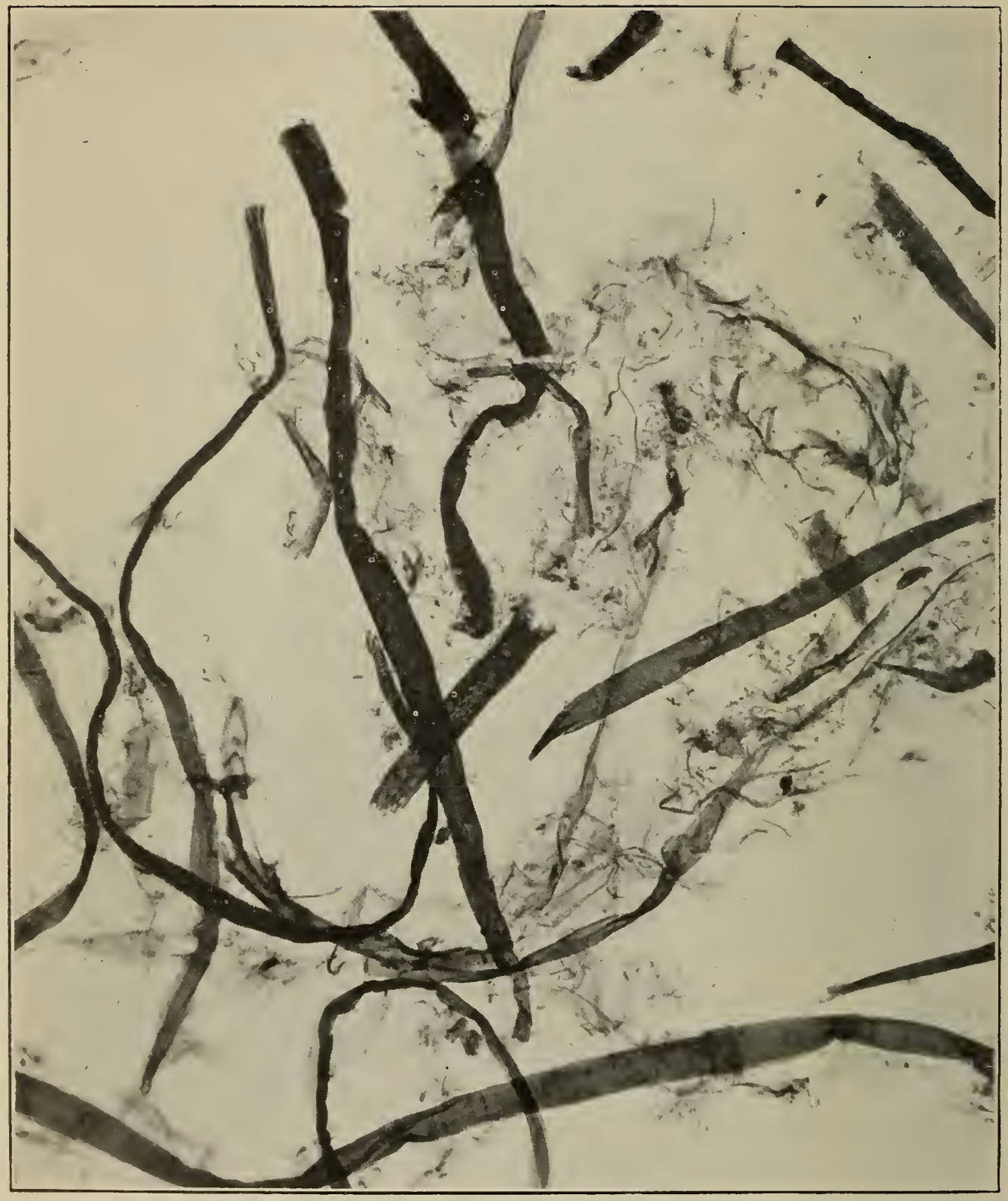

Figure 4.-Highly purified wood fiber, $\times 100$ After completion of beating (7 hours). After jordanning. 
Data on the series of rosin-sized papers indicate the importance of acidity control when the combined properties of high stability and good writing quality are desired. The findings are in accord with previous experience in the bureau mill as to the correct acidity for optimum sizing results. ${ }^{15}$

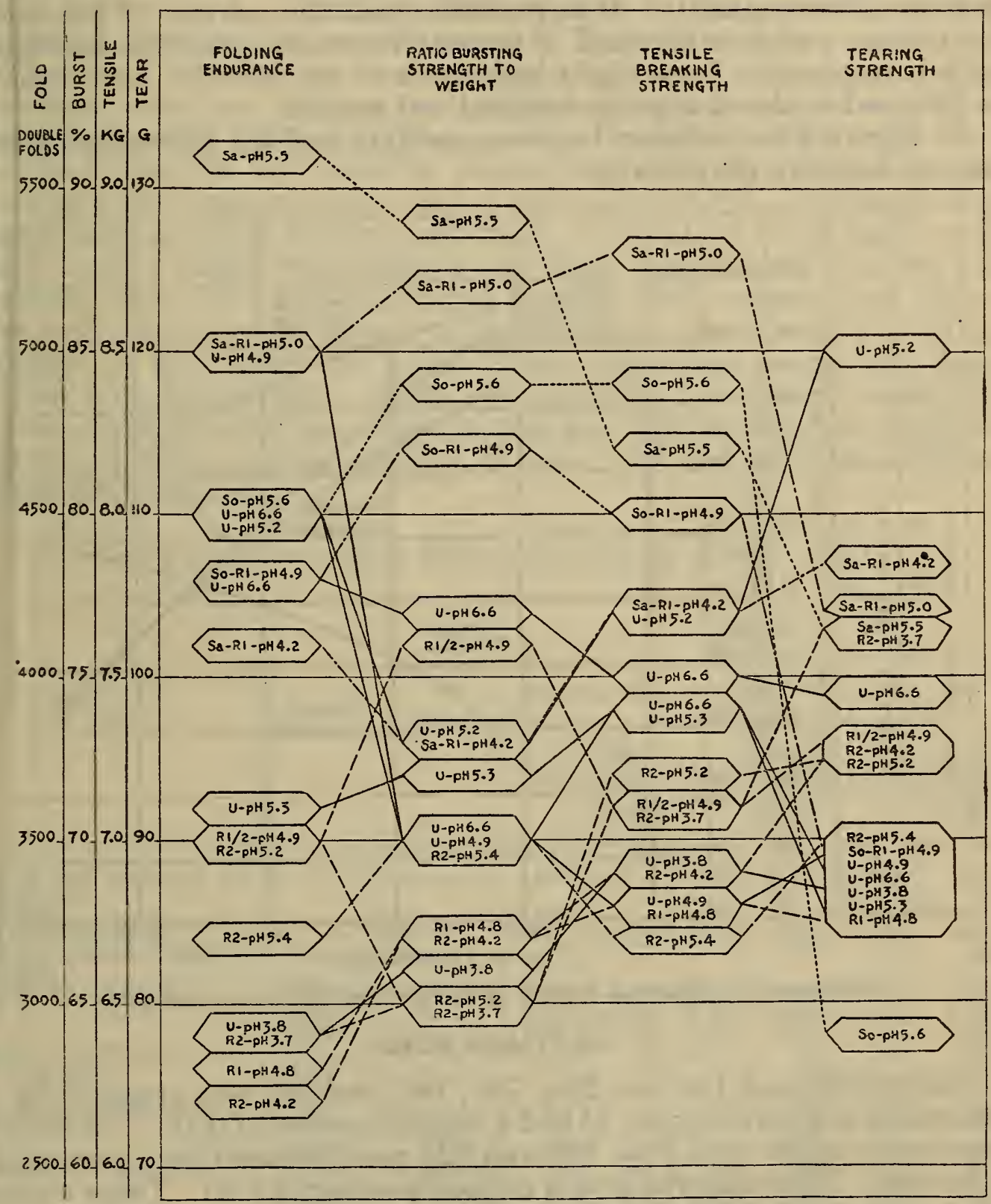

FIGURE 5.-Sirength properties of unsized and beater-sized papers

U....Unsized. $\quad$ KEY

R.-.-Rosin sized. Number following indicates per cent rosin used.

Sa... Starch sized. Starch prepared by acid process.

So...-Starch sized. Starch prepared by oxidation process.

Unsized.
$\ldots \ldots-$ Rosin sized.
............ Starch sized.

_..... Rosin and starch sized

The amount of rosin used in sizing was chosen arbitrarily. Other experiments made with a view to determining the minimum required

15 M. B. Shaw, Hydrogen Ion Concentration in the Paper Mill, Paper Trade Jour., vol. 81, No. 10, pp. 93-96, Sept. 3, 1925 . 
amount of rosin indicate that the 2 per cent used was considerably greater than that actually required to effectually size this fiber.

In general the rosin-sized papers had somewhat less strength than the unsized papers. The initial alpha cellulose content was slightly lower and the copper number slightly higher than those of the unsized papers. These differences are much less apparent in the case of tho papers of lower acidity. It is probable that the contact of the acidcontaining paper (when acid is present in excess) with the hot drier rolls is responsible for a slight hydrolysis of the cellulose fibers which is reflected in the change in chemical test results.

In Figure 6 the relation between stability and the $\mathrm{pH}$ values of the papers is shown graphically.

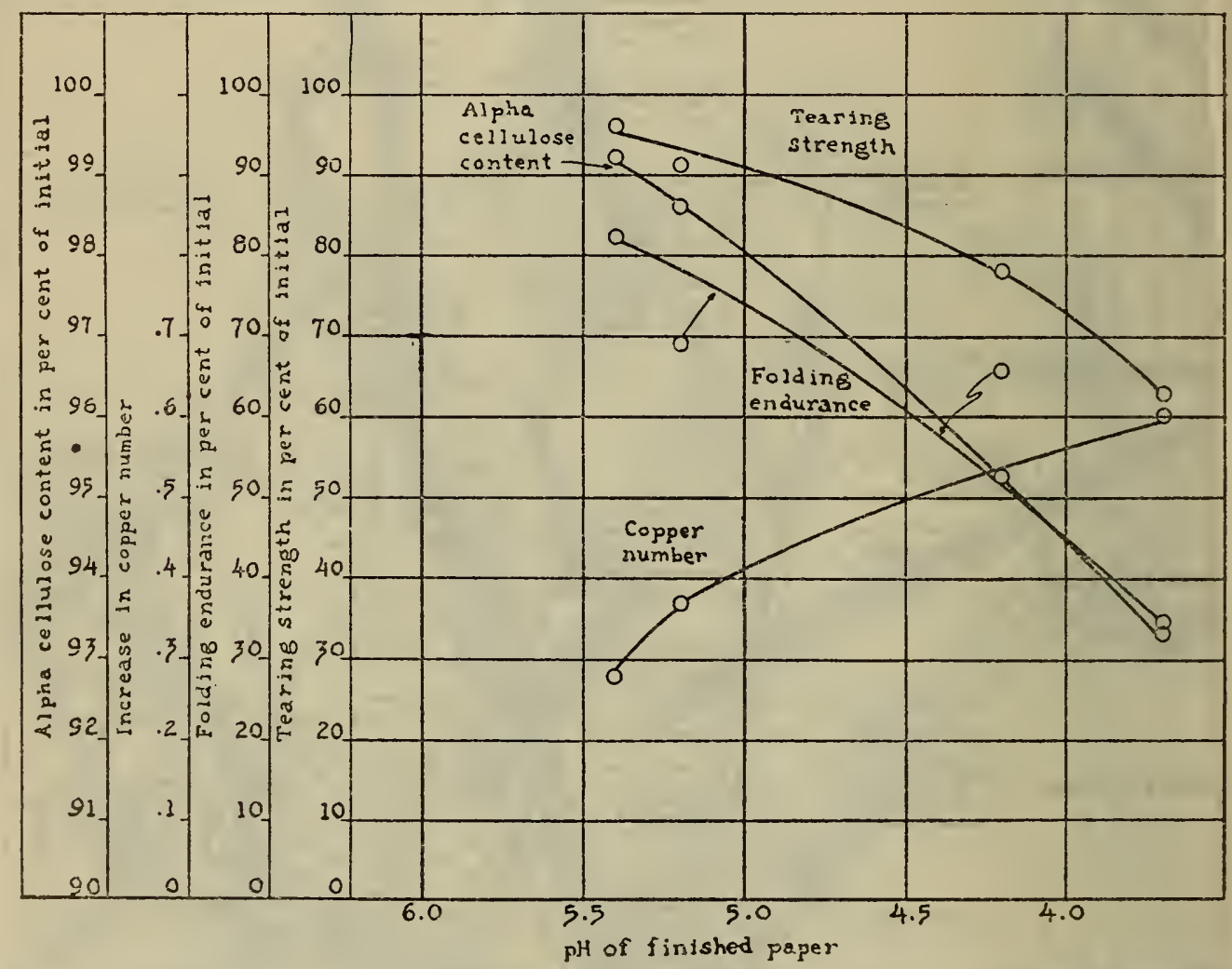

FIGURE 6.-Effect of acidity of rosin-sized papers on stability

(b) STARCH SIZED

The starch used for runs Nos. 791, 794, and 793 was prepared by a process of acid hydrolysis. It had a copper number of 0.18 . The starch product used for runs Nos. 822 and 824 was prepared by a process of oxidation. This material had a copper number of 0.68 . These starch runs were made chiefly for the purpose of studying the effect of beater starch on the properties of the papers. No complete study of starch sizing itself was intended at this time. In general beater sizing with starch increased the bursting strength and folding endurance, and decreased the tearing strength of the paper. The presence of starch had no adverse affect upon the stability of the papers, and in several cases apparently effected a slight improvement in this respect. Table 3 contains the data relative to the beating interval, sizing of the stock, and tests of the machine-made papers.

The retentions of starch in the papers varied from about 25 to 50 per cent. 


\section{SURFACE-SIZED PAPERS}

\section{(a) BOND TYPE}

(1) Basic Papers used for Surface Sizing.-Three different basic papers were employed in the study of the effect of surface sizing on the properties of the papers. Following are described the machinemade papers used. Complete data relative to the preparation and testing of these papers may be found in Tables 5 and 6 .

Run No. 785 was an unsized paper prepared according to the standard procedure without the addition of rosin size or alum. The paper was nearly neutral, having a $\mathrm{pH}$ value of 6.6. The paper had excellent strength and stability properties. Run No. 796 was rosin sized and the finished paper had a $\mathrm{pH}$ value of 4.9 . Although the paper contained but 0.5 per cent rosin, it appeared to be fairly well sized, only a slight feathering of ink lines being noted in some instances. Run No. 787 duplicated run No. 796, except that 1 per cent rosin was used in sizing. The $\mathrm{pH}$ of the paper was 4.8. The strength of this paper was good though somewhat lower than that of runs Nos. 785 or 796 . While the stability of the paper was high, it was slightly lower than that of run No. 796, which fact may be attributed to the greater amount of rosin used and to the somewhat higher acid content.

TABLE 5.-Test results of basic papers used for surface sizing ${ }^{1}$

\begin{tabular}{|c|c|c|c|c|c|c|c|c|}
\hline \multirow{3}{*}{ Item } & \multirow{3}{*}{$\begin{array}{l}\text { Machine } \\
\text { direction }\end{array}$} & \multirow{3}{*}{ Units } & \multicolumn{6}{|c|}{ Basic paper } \\
\hline & & & \multicolumn{2}{|c|}{ Run No. 785} & \multicolumn{2}{|c|}{ Run No 796} & \multicolumn{2}{|c|}{ Run No. 787} \\
\hline & & & $\begin{array}{l}\text { Origi- } \\
\text { nel }\end{array}$ & $\mid \begin{array}{c}\text { Heated } \\
\text { at } 100^{\circ} \\
\text { C. for } \\
72 \text { hours }\end{array}$ & $\begin{array}{c}\text { Origi- } \\
\text { nal }\end{array}$ & $\begin{array}{c}\text { Heated } \\
\text { at } 100^{\circ} \\
\text { C. for } \\
72 \text { hours }\end{array}$ & $\begin{array}{l}\text { Origi- } \\
\text { nal }\end{array}$ & $\begin{array}{l}\text { Eleated } \\
\text { at } 100^{\circ} \\
\text { C. for } \\
72 \text { hours }\end{array}$ \\
\hline $\begin{array}{l}\text { Weight (500 sheets, } 25 \text { by } \\
40 \text { inches). }\end{array}$ & & Pounds. & 56.8 & 57.0 & 55.3 & 54.8 & 55.4 & 54.9 \\
\hline Thickness..... & & Incb & 0.0038 & & 0.0036 & & 0.0038 & \\
\hline Bursting strength & & Points & 43.6 & 42.7 & 41.8 & 42.6 & 37.3 & 38.4 \\
\hline Ratio of bursting strength to & -..... & Per cent.... & & & & & & 70 \\
\hline Folding endurance....... & With...- & Double folds & 3,990 & 3,880 & 3,710 & 3,180 & 2,960 & 2,280 \\
\hline & $\begin{array}{l}\text { Across.-- } \\
\text { Average. }\end{array}$ & do...-. & $\begin{array}{l}4,500 \\
4,250\end{array}$ & $\begin{array}{l}4,470 \\
4,180\end{array}$ & $\begin{array}{l}3,300 \\
3,510\end{array}$ & $\begin{array}{l}2,810 \\
3,000\end{array}$ & $\begin{array}{l}2,540 \\
2,750\end{array}$ & $\begin{array}{l}2,270 \\
2,280\end{array}$ \\
\hline $\begin{array}{l}\text { Folding endurance in per } \\
\text { cent of initial. }\end{array}$ & $\begin{array}{l}\text { With } \\
\text { Across.- }\end{array}$ & Per cant. & (n) & $\begin{array}{l}97 \\
99\end{array}$ & (n) & $\begin{array}{l}85 \\
86\end{array}$ & $-\infty$ & $\begin{array}{r}77 \\
89\end{array}$ \\
\hline Tensile breaking strength.. & $\begin{array}{l}\text { Average. } \\
\text { With...- }\end{array}$ & $\mathrm{Kg}$ & 9.2 & 98 & 8.8 & $\begin{array}{r}86 \\
9.0\end{array}$ & 8.5 & $\begin{array}{r}83 \\
8.4\end{array}$ \\
\hline & Across_- & & $\begin{array}{l}5.8 \\
7.5\end{array}$ & 5.7 & $\begin{array}{l}5.3 \\
7.1\end{array}$ & $\begin{array}{l}5.3 \\
7.2\end{array}$ & $\begin{array}{l}5.2 \\
6.9\end{array}$ & $\begin{array}{l}5.2 \\
6.8\end{array}$ \\
\hline Elongation at rupture.- & With...- & Per cont. & 2.7 & 2.8 & 2.8 & 2.8 & 2.7 & 2.8 \\
\hline & Across_-- & & $\begin{array}{l}7.7 \\
5.2\end{array}$ & 7.7 & $\begin{array}{l}7.7 \\
5.3\end{array}$ & $\begin{array}{l}7.9 \\
5.3\end{array}$ & $\begin{array}{l}7.8 \\
5.3\end{array}$ & 7.9 \\
\hline Tearing strength.. & With...- & g... & 96.1 & 88.2 & 96.4 & 85.6 & 93.1 & 86.6 \\
\hline & Across-- & & $\begin{array}{r}101.3 \\
98.7\end{array}$ & 94.9 & 99.4 & 90.4 & 99.8 & 85.5 \\
\hline Tearing strength in per cent & With & Per cent. &..--1 & 92 & $\ldots . . .$. & 89 & ...... & 93 \\
\hline of initi & $\begin{array}{l}\text { Across.- } \\
\text { Average. }\end{array}$ & & & $\begin{array}{l}94 \\
93\end{array}$ & & $\begin{array}{l}91 \\
90\end{array}$ & & $\begin{array}{l}86 \\
90\end{array}$ \\
\hline
\end{tabular}

1 The data were composited from the values given in Table 6 .

Approzimately pounds per square inch.

(2) Surface-Sizing Baths.-A brief description is given below of the different solutions used in surface sizing.

(a) A 4 per cent solution of glue having a $\mathrm{pH}$ value of 6.0 . 
(b) A 4 per cent solution of glue to which 7 per cent alum (based on the weight of glue) was added. This solution had a $\mathrm{pH}$ value of 4.2 .

(c) A 4 per cent solution of glue to which one-fourth per cent formaldehyde (based on the weight of glue) was added. The $\mathrm{pH}$ of this solution was 5.5.

(d) A 4 per cent starch solution having a pH of 7.3. The starch product used was specially prepared for surface sizing by a process of acid hydrolysis. It had a copper number of 0.61 .

(e) This solution was the same as $(d)$, except that it contained 2 per cent alum (based on the weight of starch). The $\mathrm{pH}$ of the solution was 5.4.

$(f)$ A 4 per cent starch solution having a $\mathrm{pH}$ of 7.2. The starch product used was specially prepared for surface sizing by an oxidation process. The starch had a copper number of 0.94 .

$(g)$ This solution was the same as $(f)$, except that it contained 2 per cent alum (based on the weight of starch). The $\mathrm{pH}$ of the solution was 4.6 .

Complete data on the various surface-sizing runs, together with the test results obtained on the sized papers, are given in Table 6 .

Control samples corresponding to each of the surface-sizing runs were tested individually for strength and stability. These control samples were taken immediately before and after each surface-sizing treatment so as to be as representative as possible of the portion of paper sized. In the case of runs Nos. 185 to 189 inclusive, however, one sample of the basic paper, taken before and after each pair of sizing treatments made with and without alum present in the starch solution, served as a control sample for both runs. A composite of the results on all the control samples of basic papers makes up the data which are presented in Table 5 . In Table 6 are given the data which were obtained on the individual control samples together with those which were obtained on the corresponding surface-sized papers.

In general, surface sizing with glue or starch resulted in marked increases in bursting strength, tensile breaking strength, elongation, and folding endurance. The tearing strength alone underwent a decrease. With the exception of the folding: endurance the magnitude of the various strength changes was roughly in proportion to the absorbency of the basic paper, or to the amount of glue or starch taken up by the sheet. These changes are shown graphically in Figures $7 \mathrm{a}$ and $7 \mathrm{~b}$.

All the papers of the series were of exceptionally high stability, as regards the resistance of such properties as folding endurance, tearing strength, alpha cellulose content, and copper number to the effects of the heat treatment to $100^{\circ} \mathrm{C}$. for 72 hours. In all cases upwards of 80 per cent of the initial folding endurance was retained after heat treatment. Papers surface sized with glue or starch containing alum were found to be no less stable than in corresponding cases where alum was not present in the sizing bath. This points to the relative harmlessness of surface acid. Apparently as pointed out by Kohler and Hall, ${ }^{16}$ all acid present in paper is not necessarily harmful. The data indicate that evidence as to harmful acidity which is based on estimates of total acidity, or on the $\mathrm{pH}$ values of aqueous

10 See lootnoto 9, p. 769. 


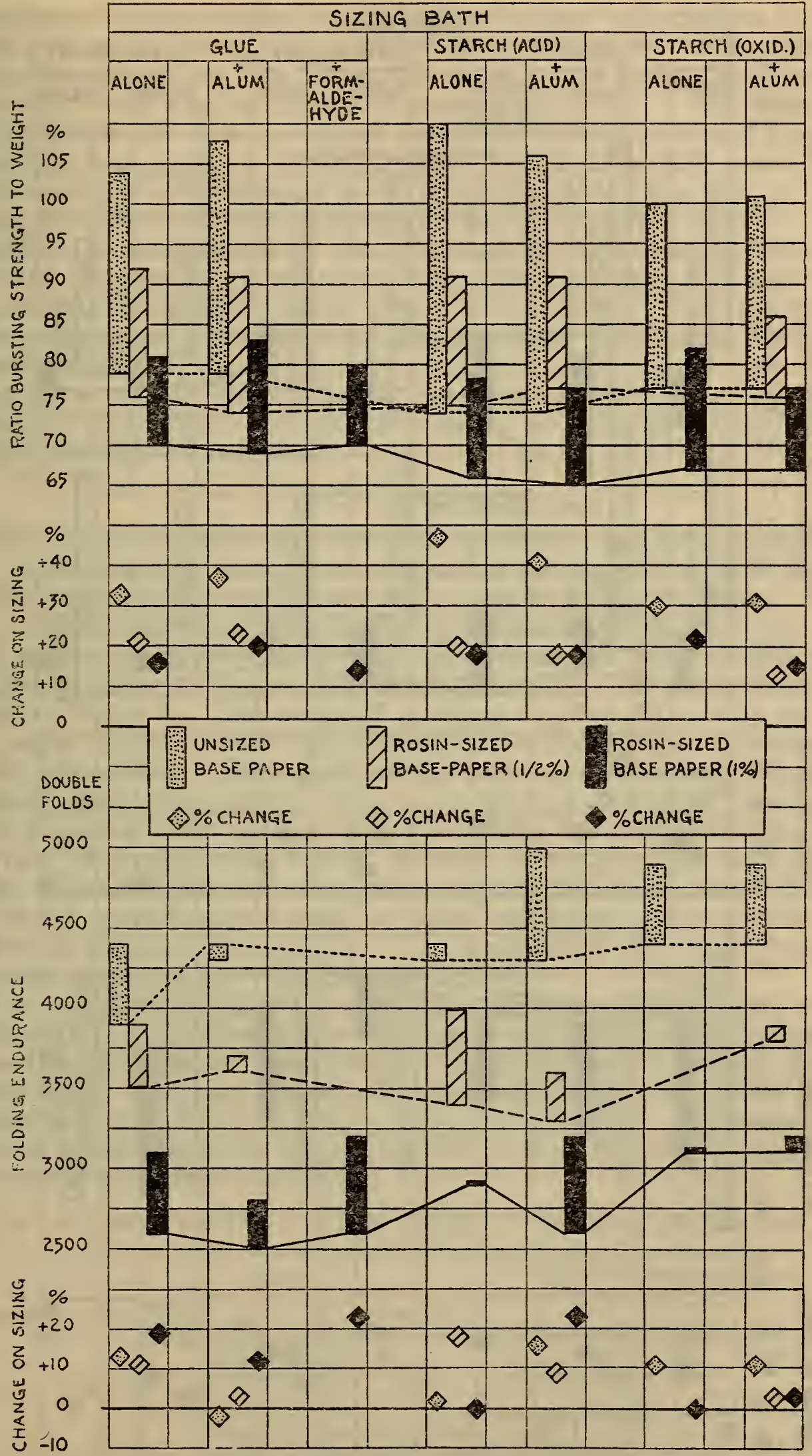

\section{FIGURE 7a.-Effect of surface sizing on the strength of papers}

The strength values of basic papers and surface-sized papers are incicated by the heights (read

$\xi$ on the scale) of the upper and lower ends of the bars. The total length of each bar thus shows the change due to surface sizing. The bars are connected by pattern lines. These show the initial values.

$79688-31-2$ 


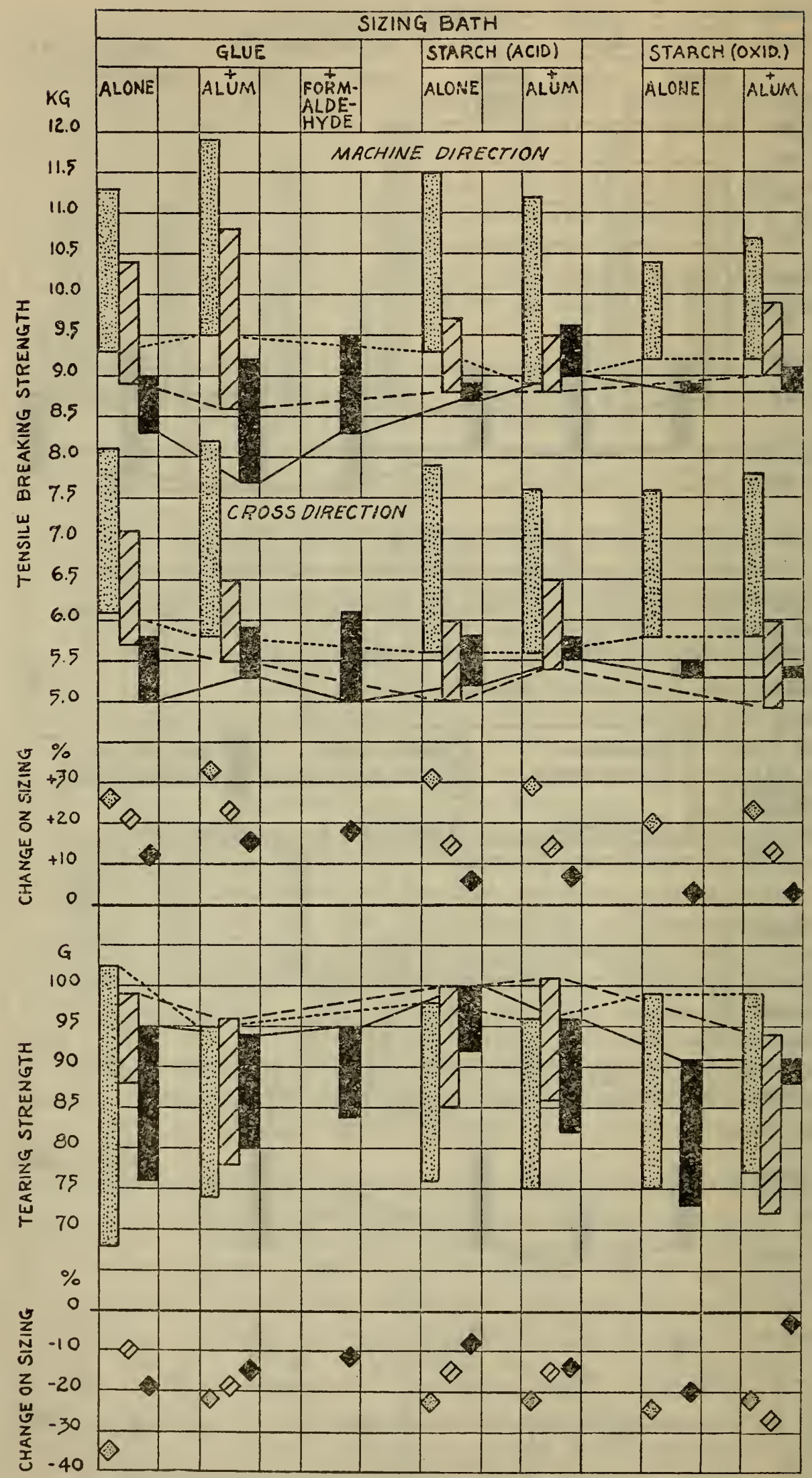

FIGURE 7b.-Effect of surface sizing on the strength of papers

Thestrength values of basic papers and surface-sized papers are indicated by the"heights (read on the scale) of the upper and lower ends of the bars. The total length of each bar thus shows the change due to surface sizing. The bars are connected by pattern lines. These show the initial values. 
extracts of paper, may be misleading unless information is also available as to the acidity or $\mathrm{pH}$ of the basic paper. For example, in surface-sizing run No. 174 a rosin-sized paper having a $\mathrm{pH}$ of 4.8 was sized with a glue solution having a $\mathrm{pH}$ of 4.2 . The resultant paper had a pH of 4.4, and yet was more stable in several respects than the base paper. In this respect the Kohler-Hall method for determining acidity appears to be of considerable value also as they state, for differentiating between internal and external acidity. The stability, as determined by the decrease in alpha cellulose content and the increase in copper number on heat treatment was improved somewhat when the papers were surface sized. This protective effect was somewhat greater for the glue-sized papers than for those sized with starch.

As far as can be determined by the tests applied, the use of formaldehyde as a preservative in glue sizing is without marked effect on the stability of the paper.

\section{(b) CURRENCY TYPE}

The character and strength of the papers that had been made from the highly purified wood fibers suggested the possibility of their use in the preparation of certificate and currency types of papers. With this in mind, three unsized papers were made from the fiber and surface sized with glue. The beating procedure and other details were similar to those for papers previously described. The test data are given in Table 7. The paper of machine run No. 825A was run off the paper machine as an approximately 61 -pound paper $(500$ sheets, 25 by 40 inches). The weight of the paper after surface sizing was approximately 63 pounds. The stock for run No. $825 \mathrm{~B}$ was taken from the same batch as that for run No. 825A but the paper was made heavier, 68-pound basis weight, in order to obtain more bulk in the sheet. For run No. 826 the pulp was prepared in the same manner as for the preceding two runs, but clay was added to the pulp in the beater to improve the opacity. The amount of clay added was 10 per cent based on the weight of the furnish.

The test data given in the table show that these papers had excellent strength properties. The bursting strength and folding endurance exceeded the present specification requirements for United States Government currency paper and they apparently possessed other qualities considered desirable in paper of this kind. Unfortunately there is no test available for judging how well paper will withstand the wear peculiar to paper currency.

TABLE 7.-Data on currency type papers prepared from highly purified wood fibers

\begin{tabular}{|c|c|c|c|c|c|c|c|c|c|c|}
\hline \multirow[b]{2}{*}{ Paper machine run } & \multirow[b]{2}{*}{$\begin{array}{l}\text { Surface } \\
\text { sizing } \\
\text { run No. }\end{array}$} & \multicolumn{2}{|c|}{ Weight } & \multirow[b]{2}{*}{$\begin{array}{l}\text { Thick- } \\
\text { ness }\end{array}$} & \multirow[b]{2}{*}{$\begin{array}{c}\text { Burst- } \\
\text { ing } \\
\text { strerigth }\end{array}$} & \multicolumn{2}{|c|}{$\begin{array}{l}\text { Folding endur- } \\
\text { ance }\end{array}$} & \multicolumn{2}{|c|}{ Tearingstrength } & \multirow[b]{2}{*}{ Opacity } \\
\hline & & $\begin{array}{c}500 \\
\text { sheets, } \\
17 \text { by } 22 \\
\text { inches }\end{array}$ & $\begin{array}{c}500 \\
\text { sheets, } \\
25 \text { by } 40 \\
\text { inches }\end{array}$ & & & $\begin{array}{c}\text { Ma- } \\
\text { chine } \\
\text { direc- } \\
\text { tion! }\end{array}$ & $\begin{array}{l}\text { Cross } \\
\text { direc- } \\
\text { tion }\end{array}$ & $\begin{array}{l}\text { Ma- } \\
\text { chine } \\
\text { direc- } \\
\text { tion }\end{array}$ & $\begin{array}{c}\text { Cross } \\
\text { direc- } \\
\text { tion }\end{array}$ & \\
\hline $\begin{array}{l}825 \mathrm{~A} . \\
825 \mathrm{~B} . \\
826 \ldots\end{array}$ & 190 & $\begin{array}{c}\text { Pounds } \\
22.7 \\
23.4 \\
25.3 \\
26.2 \\
22.6 \\
23.7\end{array}$ & $\begin{array}{c}\text { Pounds } \\
60.7 \\
62.6 \\
67.8 \\
70.1 \\
60.3 \\
63.5\end{array}$ & $\begin{array}{l}\text { Inch } \\
0.0040 \\
.0038 \\
.0042 \\
.0041 \\
.0038 \\
.0037\end{array}$ & $\begin{array}{c}\text { Points }{ }^{1} \\
44.8 \\
63.2 \\
49.5 \\
68.0 \\
38.8 \\
55.5\end{array}$ & $\begin{array}{c}\text { Double } \\
\text { folds } \\
4580 \\
3960 \\
5200 \\
4280 \\
3870 \\
3640\end{array}$ & $\begin{array}{c}\text { Double } \\
\text { folds } \\
7270 \\
5400 \\
5940 \\
5950 \\
1980 \\
3250\end{array}$ & \begin{tabular}{r}
\multicolumn{1}{c}{$G$} \\
81.4 \\
80.8 \\
110.6 \\
91.6 \\
96.2 \\
78.8
\end{tabular} & $\begin{array}{r}G \\
93.6 \\
84.8 \\
109.0 \\
93.2 \\
89.2 \\
74.4\end{array}$ & $\begin{array}{l}79.7 \\
77.3 \\
82.5 \\
79.1 \\
85.3 \\
82.7\end{array}$ \\
\hline
\end{tabular}

I Approzimately, pounds per square inch. 


\section{CONCLUSIONS}

1. High-grade bond papers were made from highly purified wood fibers by the following procedure, which was found to give the best results with the fibers under study. The beating of the stock was conducted in such a manner as to minimize cellulose gel formation, and yet obtain the desired fraying out and fibrillation of the individual fibers. This was satisfactorily accomplished by means of a 7-hour beating, during the course of which the roll was very gradually lowered. The beaten stock was lightly brushed in the Jordan.

2. When so beaten the strength exceeded that required by the Government for the highest grade writing papers; and for currency type paper the strength requirements for United States currency were exceeded.

3. The stability of rosin-sized papers in the accelerated aging test was seriously impaired by the presence of excess alum, but with the control of acidity at $\mathrm{pH} 5.0$ a highly stable, well-sized paper was produced.

4. Starch used as sizing by addition in the beater did not reduce the stability in the aging test.

5. Surface sizing with glue or starch improved the resistance to the aging test, especially with glue sizing.

6. Moderate amounts of alum (used as a preservative for glue or starch in the surface sizing baths) were found not deleterious.

\section{ACKNOWLEDGMENT}

The authors are indebted to M. J. O'Leary ${ }^{17}$ and G. O. Stone ${ }^{18}$ who assisted in these studies.

Washington, August 25, 1931. 